Case Report

\title{
Decontamination Using a Desiccant with Air Powder Abrasion Followed by Biphasic Calcium Sulfate Grafting: A New Treatment for Peri-Implantitis
}

\author{
Giorgio Lombardo, ${ }^{1}$ Giovanni Corrocher, ${ }^{1}$ Angela Rovera, ${ }^{1}$ Jacopo Pighi, \\ Mauro Marincola, ${ }^{2}$ Jeffrey Lehrberg, ${ }^{3}$ and Pier Francesco Nocini ${ }^{1}$ \\ ${ }^{1}$ Clinic of Dentistry and Maxillofacial Surgery, Policlinico G.B. Rossi, University of Verona, Piazzale L.A. Scuro 10, 37134 Verona, Italy \\ ${ }^{2}$ Department of Dental Medicine, University of Cartagena, Avenida del Consulado \# Calle 30 No. 48-152, Cartagena, \\ Bolivar 130011, Colombia \\ ${ }^{3}$ Department of Biomaterials, Implant Dentistry Centre, 501 Arborway, Jamaica Plain, Boston, MA 02130, USA
}

Correspondence should be addressed to Giorgio Lombardo; giorgio.lombardo@univr.it

Received 2 February 2015; Revised 31 March 2015; Accepted 15 April 2015

Academic Editor: Jamil A. Shibli

Copyright (C) 2015 Giorgio Lombardo et al. This is an open access article distributed under the Creative Commons Attribution License, which permits unrestricted use, distribution, and reproduction in any medium, provided the original work is properly cited.

Peri-implantitis is characterized by inflammation and crestal bone loss in the tissues surrounding implants. Contamination by deleterious bacteria in the peri-implant microenvironment is believed to be a major factor in the etiology of peri-implantitis. Prior to any therapeutic regenerative treatment, adequate decontamination of the peri-implant microenvironment must occur. Herein we present a novel approach to the treatment of peri-implantitis that incorporates the use of a topical desiccant (HYBENX), along with air powder abrasives as a means of decontamination, followed by the application of biphasic calcium sulfate combined with inorganic bovine bone material to augment the intrabony defect. We highlight the case of a 62 -year-old man presenting periimplantitis at two neighboring implants in positions 12 and 13, who underwent access flap surgery, followed by our procedure. After an uneventful 2-year healing period, both implants showed an absence of bleeding on probing, near complete regeneration of the missing bone, probing pocket depth reduction, and clinical attachment gain. While we observed a slight mucosal recession, there was no reduction in keratinized tissue. Based on the results described within, we conclude that the use of HYBENX and air powder abrasives, followed by bone defect grafting, represents a viable option in the treatment of peri-implantitis.

\section{Introduction}

Peri-implantitis is a condition that affects the mucosa and bone surrounding dental implants and is characterized by crestal bone loss $[1,2]$. Depending on the qualification criteria, the incidence of peri-implantitis ranges from $18.8 \%$ to $51.9 \%$ [3-5]. It is generally accepted that the colonization of deleterious bacteria in the peri-implant microenvironment plays a major role in the etiology of peri-implantitis $[1,6-$ 8]. Polymicrobial communities that colonize different microhabitats within the mouth are referred to as a biofilm $[9,10]$. Similar to periodontitis, treatment modalities aimed at correcting peri-implantitis include the reduction or elimination of deleterious bacteria within the biofilms that coat the oral surfaces $[11,12]$.
Removal of oral biofilms, or the decontamination of the peri-implant microenvironment in patients suffering from peri-implantitis, can be achieved through both surgical and nonsurgical means [11, 12]. Proposed treatments for the decontamination of microenvironments during periimplantitis include antibiotic and antiseptic treatment (both local and systemic), mechanical debridement, and laser treatment [13]. Surgical techniques are also used in the treatment of peri-implantitis, with the rationale that surgery grants increased access to the spaces inhabited by deleterious bacteria $[13,14]$. However, strong evidence supporting any particular therapy in the treatment of peri-implantitis has yet to be established $[13,14]$. In light of this, we attempted to treat a case of peri-implantitis using a topical desiccant (HYBENX Oral Tissue Decontaminant, EPIEN Medical, 


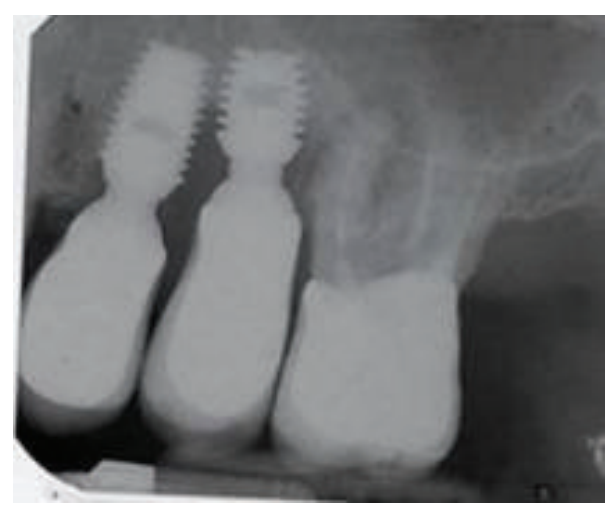

FIgURE 1: The baseline periapical radiograph indicated a deep interproximal peri-implant bone lesion.

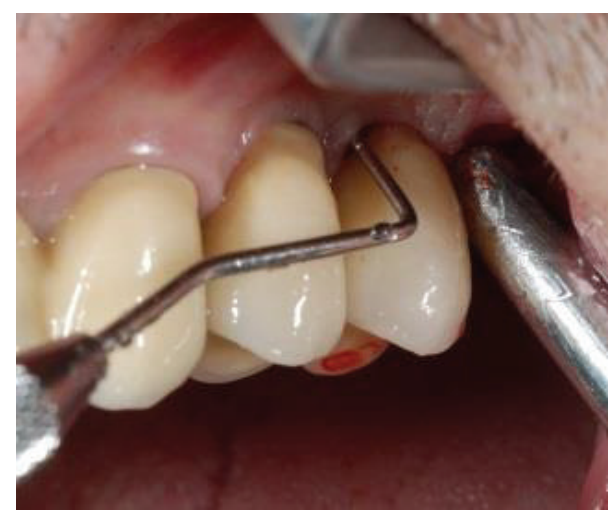

FIGURE 2: Initial probing revealed a deep peri-implant pocket between 2 short, single-crown locking taper implants, in positions 12 and 13.

Inc.) as an adjunct to air powder abrasion (Airflow, EMS), followed by the application of an inorganic bone composite comprised of a mixture of bovine bone material (Bio-Oss, Geistlich Biomaterials) mixed with biphasic calcium sulfate (BondBone, MIS Implants Technologies Ltd.). HYBENX is an extremely hygroscopic solution that theoretically functions by denaturing the attachment proteins used by bacteria to adhere to the implant surface. This allows the more efficient subsequent removal of biofilm microbes. To our knowledge, no study using a topical desiccant as an adjunct to air powder abrasives has been published to date.

Here we report the treatment protocol and two-year follow-up of a 62-year-old patient who was treated using our novel surgical protocol for peri-implantitis. Based on the successful outcome our patient exhibited, we conclude that the use of a HYBENX as an adjunct to air powder abrasion, followed by composite bone grafting using inorganic bovine bone mixed with biphasic calcium sulfate, represents a possible future treatment for peri-implantitis that warrants further consideration and study.

\section{Case Report}

A 62-year-old man reported discomfort and bleeding that occurred while brushing around his two single crown

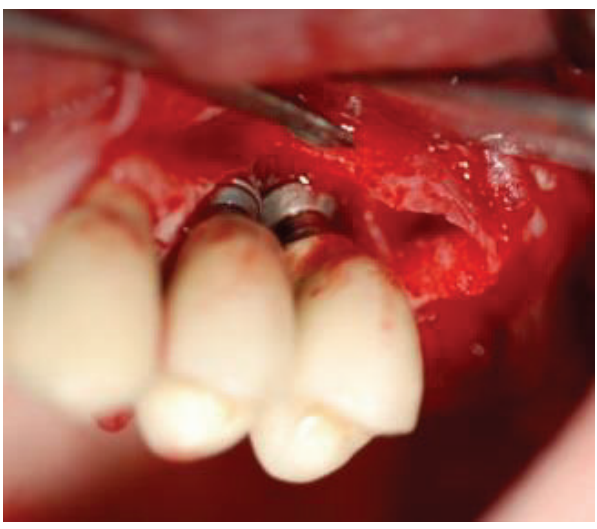

FIgURE 3: After elevation of the vestibular and palatal full thickness flaps, a crater-like defect characterized by interproximal bone loss was observed around the implants.

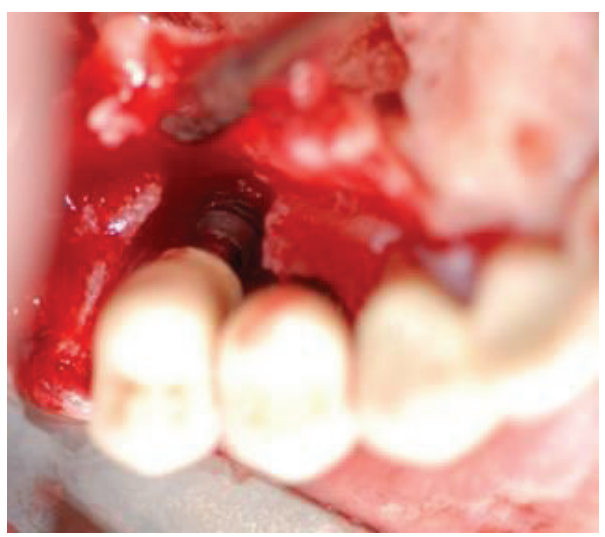

FIGURE 4: After elevation of the vestibular and palatal full thickness flaps, a crater-like defect characterized by interproximal bone loss was observed around the implants.

implants (upper left premolars: tooth numbers 12 and 13). Periapical radiographs revealed a large apical lesion adjacent to the neighboring molar and a bone loss pattern suggestive of peri-implantitis around the indicated implants (Figure 1). Probing pocket depths ranged from 7 to $9 \mathrm{~mm}$ (Figure 2). Initial treatment included the nonsurgical mechanical debridement of implants using ultrasonic devices and reinstruction in oral hygiene techniques. This initial treatment unfortunately resulted in insignificant reductions of pocket depths and inflammation.

Following the initial nonsurgical treatment, the option of removing the prosthesis to allow submerged healing was presented to and declined by the patient. After discussing the inherent risks involved, the patient gave written consent and agreed to proceed with open debridement and decontamination, followed by guided bone regeneration using bone composite [15].

In order to minimize clinical signs of inflammation, a single course of low abrasive air powder (Airflow) was implemented two weeks before surgery.

The surgical procedure is described as follows: briefly, after local infiltration of a $2 \%$ lidocaine solution with 


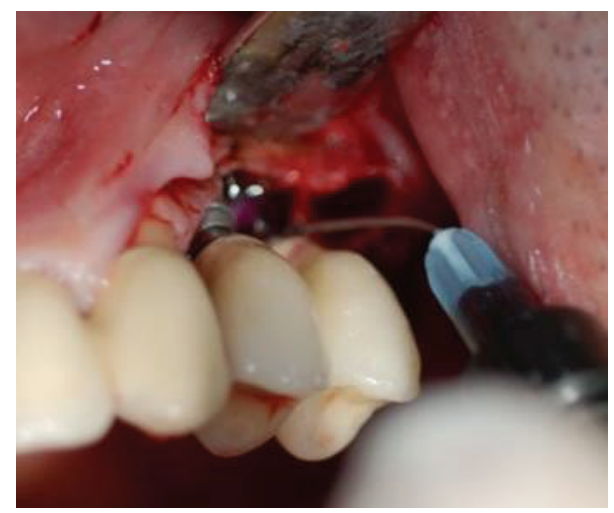

Figure 5: HYBENX was administered on the implant surface for 60 seconds and then thoroughly rinsed away with saline.

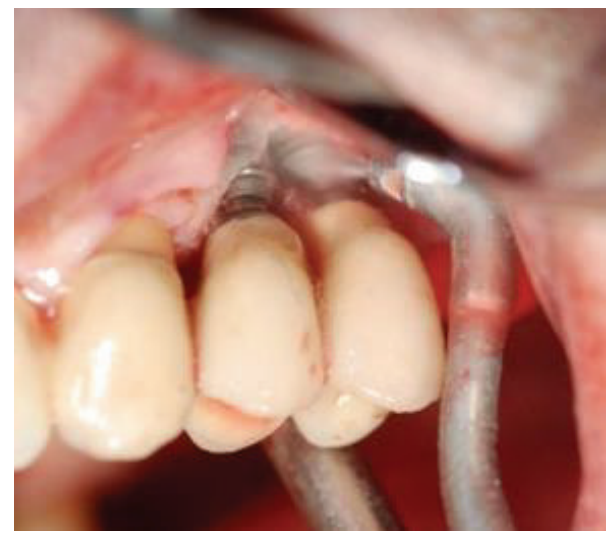

Figure 6: Debridement of the implant surfaces using air powder abrasion for 60 seconds.

$1 \mathrm{mcg} / \mathrm{mL}$ epinephrine, sulcular incisions were made on the buccal and lingual/palatal side in an effort to preserve soft tissue. Full thickness flaps were then elevated with a periosteal release to allow for adequate flap mobilization and coronal advancement at the time of closure.

Interproximal tissue was then removed and-after a thorough degranulation of the osseous defects-surgical exposure of the coronal portion of the implants was provided. Smoothening of buccally and supracrestally exposed implant parts was performed with the use of rotating burs (i.e., implantoplasty) (Figures 3 and 4) [16, 17]. The surface decontamination procedure consisted of a 3-step protocol that was repeated twice:

(1) Application of HYBENX to the defect and implant surface, with 60-second incubation period (Figure 5).

(2) Abundant irrigation of the defect with saline solution.

(3) Administration of sodium bicarbonate-based abrasive air powder treatment (Airflow) to all contaminated and exposed parts of the implant surface for 60 seconds (Figure 6).

After the second round of surface decontamination had concluded, bone defects were filled with a composite graft that

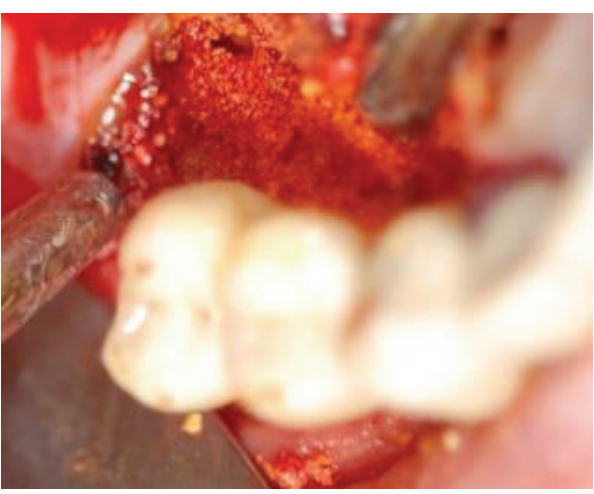

Figure 7: Following decontamination of the implant surface, a mixture of biphasic calcium sulfate and inorganic bovine bone were applied to defect at the buccal and palatal location (without a membrane).

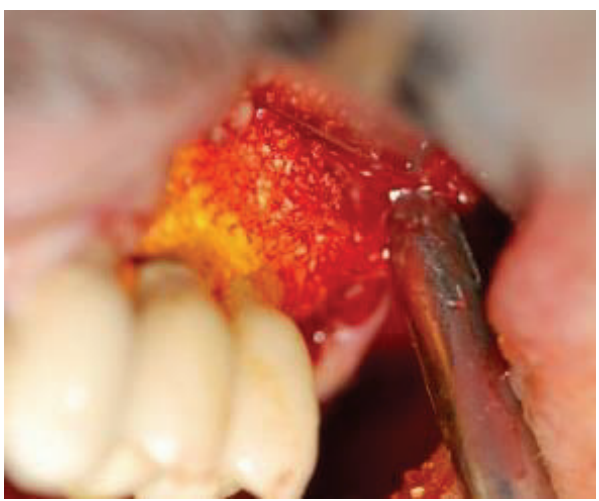

FIgURE 8: Following decontamination of the implant surface, a mixture of biphasic calcium sulfate and inorganic bovine bone were applied to defect at the buccal and palatal location (without a membrane).

was created by mixing the inorganic portion of bovine bone (Bio-Oss) with a synthetic biphasic calcium sulfate material (BondBone). Bio-Oss $(0.5 \mathrm{mg})$ and BondBone $(0.5 \mathrm{~g})$ were combined with Rifampicin (1 vial, Sanofi-Aventis) to produce the composite. Because the composite bone graft possesses the ability to harden in the presence of blood and saliva, we decided to forgo the use of graft retaining membranes (Figures 7 and 8). The flap was then mobilized and advanced in order to obtain a primary tension-free closure (Figures 9 and 10). Following the procedure, postoperative radiographs were taken to evaluate the level of the defect filling (Figure 11).

Postoperative care included a $0.12 \%$ chlorhexidine + $0.05 \%$ cetylpyridinium chloride (CPC) rinse (GUM Paroex, Sunstar Suisse S.A.) twice daily for 2 weeks, $1 \mathrm{~g}$ of amoxicillin every 12 hours for 7 days, and $800 \mathrm{mg}$ of ibuprofen as needed for pain. Following the procedure the patient was instructed to abstain from brushing for two weeks and flossing for one month.

The patient was evaluated one week following the procedure. At two weeks, the patient was reevaluated and the sutures were removed. Four weeks after procedure the patient underwent surgical area debridement and home oral hygiene 


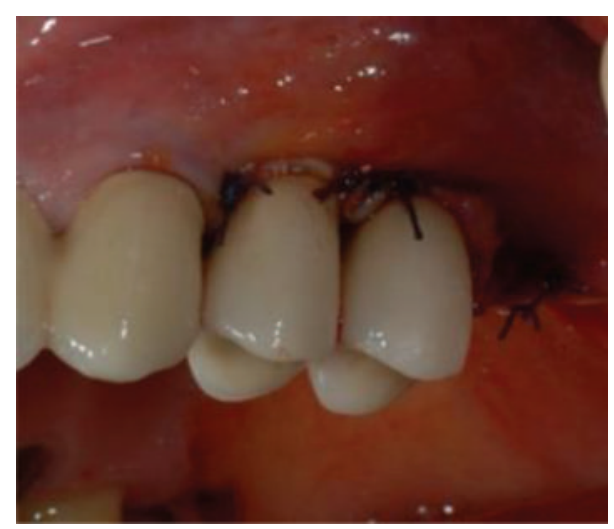

FIgURE 9: The mucoperiosteal flap was repositioned to ensure transmucosal healing and proper wound closure.

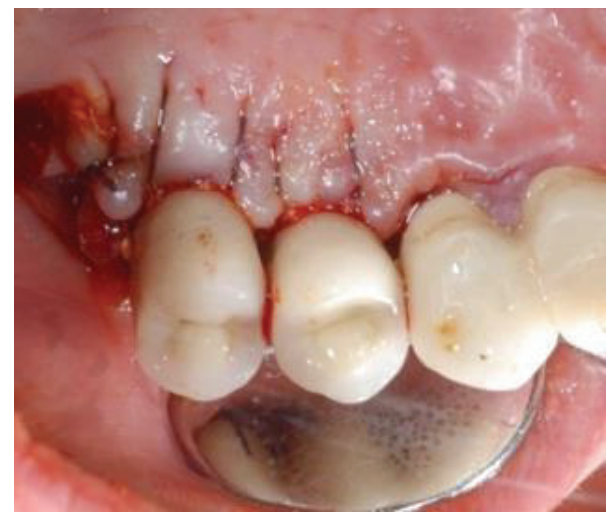

FIGURE 10: The mucoperiosteal flap was repositioned to ensure transmucosal healing and proper wound closure.

techniques were reinforced. The patient was placed on an 812 week recall schedule until the completion of treatment (2 years), during which time periapical radiographs were taken every 6 months.

\section{Results}

Measurements derived from clinical observations are summarized in Table 1 and represent the mean of four sampling sites surrounding each implant (i.e. buccal, lingual/palatal, mesial, and distal) both immediately before surgery (baseline) and at the 2-year time point.

Bone level changes and percentage of bone fill were measured using scanning intraoral radiographs with parallel technique, using Rinn centering devices (Rinn XCP Posterior Aiming Ring-Yellow, Dentsply, Elgin, IL). First boneto-implant contact changes were assessed as described by Urdaneta et al. (2010) [18]. Implant measurements taken from radiographs were calibrated to actual implant lengths by using ImageJ to calculate the pixel $/ \mathrm{mm}$ ratio of radiographs taken at baseline and after 2 years.

After an uneventful healing period of one year, clinical evaluations revealed healthy peri-implant hard and soft tissues (Figures 12 and 13). Two years after procedure, a

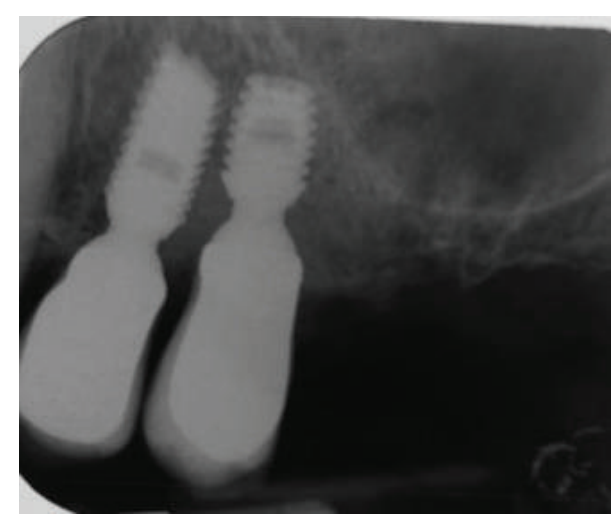

FIGURE 11: Postoperative radiograph indicating complete filling of the peri-implant defect.

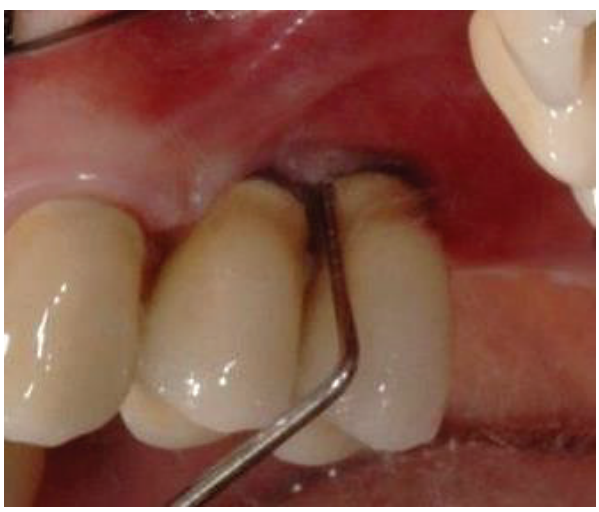

FIGURE 12: One-year after procedure, an absence of bleeding and reduced probing depth was observed.

complete absence of bleeding upon probing along with physiological probing was observed (Figures 14 and 15). A slight recession of the soft tissues without a change in the height of keratinized tissue was also observed (Table 1).

Radiograph measurements reflecting bone level changes and the percentage of bone fill are summarized in Table 2 . Radiographs revealed that the initial bony defect had been almost completely regenerated (Figure 16), and increases in radiographic first bone-to-implant contact were observed at both the mesial $(2.9 \mathrm{~mm}$ and $6.7 \mathrm{~mm}$ at numbers 12 and 13 , resp.) and distal regions $(8.0 \mathrm{~mm}$ and $5.6 \mathrm{~mm}$ at numbers 12 and 13 , resp.).

\section{Discussion}

Peri-implantitis is responsible for the majority of implant failures [3, 14, 17]. Defined as an irreversible condition with a relatively high - and possibly underreported-incidence rate, the prevention and treatment of peri-implantitis should be of the utmost concern to every clinician [3-5, 13].

Many factors come into play when choosing an appropriate treatment for peri-implantitis. Overall patient health, location of the defect, and progression of the disease are all factors that should be considered. When probing depths 
TABLE 1: Postsurgical clinical observations taken at baseline and 2 years. Baseline values were obtained immediately before surgery. Results are expressed as Mean \pm SD and are the average values of the four areas investigated. $\mathrm{BOP}=$ bleeding on probing, $\mathrm{PD}=$ probing depth, $\mathrm{MR}$ $=$ mucosal recession, $\mathrm{CAL}=$ clinical attachment level, and $\mathrm{KM}=$ keratinized mucosa width .

\begin{tabular}{lcccccccccc}
\hline \multirow{2}{*}{$\begin{array}{l}\text { Implant site } \\
\text { (tooth number) }\end{array}$} & \multicolumn{2}{c}{ PPD $(\mathrm{mm})$} & \multicolumn{2}{c}{ BOP $(\%)$} & \multicolumn{2}{c}{ MR } & \multicolumn{2}{c}{ KM } & \multicolumn{2}{c}{ CAL } \\
& Baseline & 2 years & Baseline & 2 years & Baseline & 2 years & Baseline & 2 years & Baseline & 2 years \\
\hline 12 & $7.0 \pm 1.8$ & $2.7 \pm 0.5$ & 100 & 0 & $1.2 \pm 0.7$ & $1.0 \pm 0.9$ & $2.3 \pm 0.6$ & $2.4 \pm 0.6$ & $8.2 \pm 2.3$ & $3.7 \pm 0.8$ \\
13 & $8.3 \pm 1.0$ & $2.8 \pm 0.4$ & 100 & 0 & $0.8 \pm 0.7$ & $1.4 \pm 0.5$ & $1.0 \pm 1.0$ & $1.0 \pm 1.0$ & $9.2 \pm 1.2$ & $4.1 \pm 0.8$ \\
\hline
\end{tabular}

TABLE 2: Radiographic observations observed at baseline after 2 years and expressed as variations after 2 years. Baseline values were obtained immediately before surgery. $\Delta=$ changes of values compared with baseline after 2 -year follow-up period. $r$ - $\mathrm{BF}=$ the percentage of radiographic bone fill of the defect at 2 years.

\begin{tabular}{|c|c|c|c|c|c|c|c|}
\hline \multirow{3}{*}{$\begin{array}{l}\text { Implant site } \\
\text { (tooth number) }\end{array}$} & \multicolumn{7}{|c|}{ First bone-to-implant contact (FBIC) } \\
\hline & \multicolumn{3}{|c|}{ Mesial (mm) } & \multicolumn{3}{|c|}{ Distal $(\mathrm{mm})$} & \multirow{2}{*}{$\mathrm{r}-\mathrm{BF}(\%)$} \\
\hline & Baseline & 2 years & $\Delta$ & Baseline & 2 years & $\Delta$ & \\
\hline 12 & $-3.0 \mathrm{~mm}$ & $-0.1 \mathrm{~mm}$ & $+2.9 \mathrm{~mm}$ & $-8.1 \mathrm{~mm}$ & $-0.1 \mathrm{~mm}$ & $+8.0 \mathrm{~mm}$ & $93.0 \%$ \\
\hline 13 & $-6.9 \mathrm{~mm}$ & $-0.2 \mathrm{~mm}$ & $+6.7 \mathrm{~mm}$ & $-5.8 \mathrm{~mm}$ & $-0.2 \mathrm{~mm}$ & $+5.6 \mathrm{~mm}$ & $91.6 \%$ \\
\hline
\end{tabular}

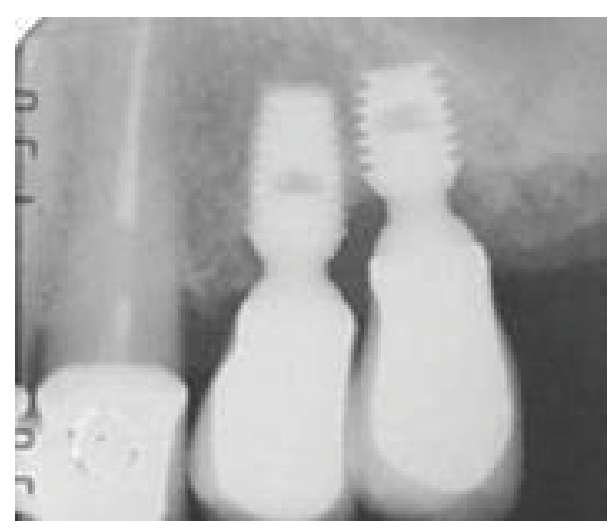

FIGURE 13: One-year postoperative radiographs depicting radiopacity at the location of the defect.

exceed $5 \mathrm{~mm}$, bleeding on probing occurs, and conventional nonsurgical options have been exhausted; then surgical intervention involving open debridement with resective or regenerative therapy should be performed [19-21].

We chose to pursue a novel course of treatment that utilized a topical desiccant and air powder abrasion to decontaminate the afflicted site, followed by grafting a mixture of biphasic calcium sulfate and inorganic bovine bone. The use of air powder abrasion during open flap surgical procedures has been shown to be an efficient decontamination measure both in vitro and in vivo [22-28]. And surfaces treated with air powder abrasives do not significantly affect the viability of human gingival fibroblasts and osteosarcoma cells, in vitro $[29,30]$. Despite the efficacious nature of air powder abrasion as highlighted in the relevant literature, defect and implant morphology can potentially diminish its effectiveness (especially in cases of narrow defects and around implant threads) [22-28, 31]. In addition, the use of adjunctive antibiotics or antiseptics to air powder abrasion has yielded favorable outcomes [32]. Bearing this in mind, we

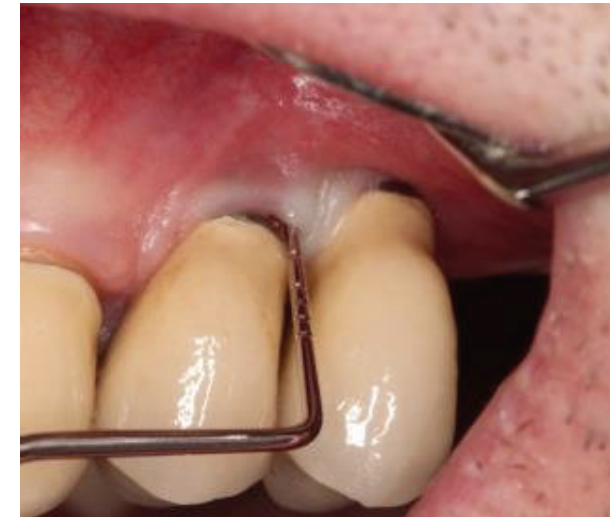

FIgURE 14: Two-year postoperative clinical examination revealed health hard and soft tissues with no bleeding and reduced probing depth (buccal and lingual/palatal probing shown).

chose to use the desiccating agent HYBENX as an adjunct to air powder abrasion.

HYBENX - an extremely hygroscopic solution comprised of hydroxymethoxybenzenesulfonic and hydroxybenzenesulfonic acid isomers, sulfuric acid, and water-has been used in the treatment of recurrent aphthous stomatitis [33]. The use of HYBENX was pursued in an attempt to boost the efficacy of our decontamination procedure, by denaturing adherence proteins used by bacteria in narrow defects and on implant threads, allowing them to be more easily rinsed away [31].

Subsequent to decontamination, we grafted a combination of inorganic bovine bone with biphasic calcium sulfate, in the absence of a membrane. Membranes (in the context of implant surgeries) serve as scaffolds to guide bone growth as well as barriers to soft tissue invasion $[34,35]$. Owing to the fact that the novel composite we used possesses the ability to harden in the presence of saliva and blood (and in light of a report indicating no significant difference between bone 


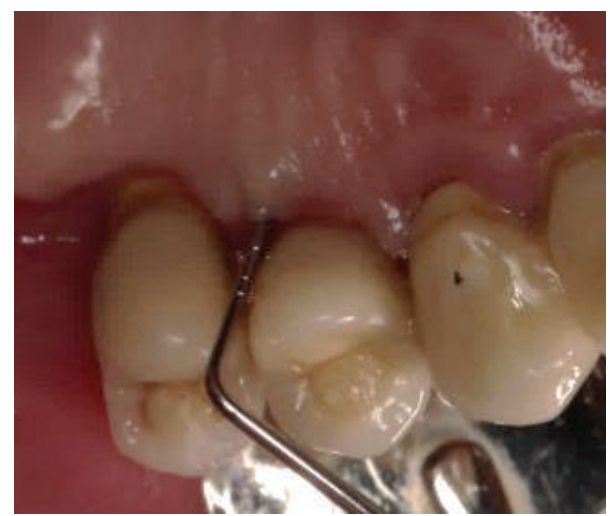

FIGURE 15: Two-year postoperative clinical examination revealed health hard and soft tissues with no bleeding and reduced probing depth (buccal and lingual/palatal probing shown).

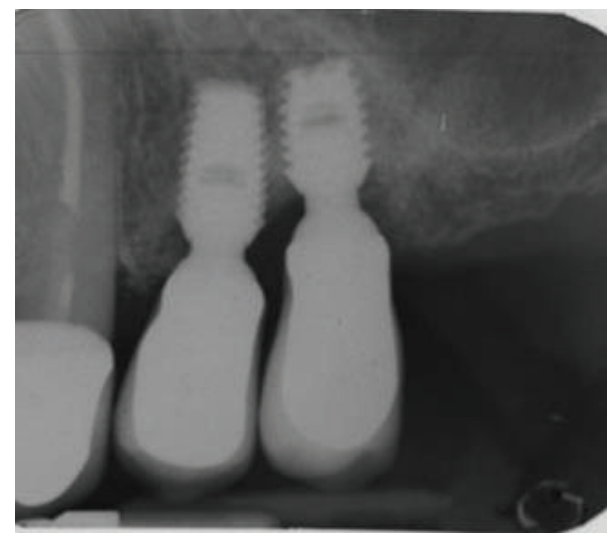

FIGURE 16: Two-year postoperative radiographs depicting radiopacity at the location of the defect, showing a near complete regeneration of the missing bone.

fill levels when comparing resorbable membranes to bone substitute alone), we decided to forgo the use of membranes [36].

\section{Conclusion}

The absence of morbidity and remarkably uneventful healing period our patient exhibited suggest that the technique described here may represent a successful procedure in the treatment of peri-implantitis. Clinical and radiographic evidence presented here corroborate the efficacy of this procedure. Based on the outcomes of this report, future work using this novel decontamination and bone grafting procedure should be considered.

\section{Conflict of Interests}

The authors declare that there is no conflict of interests regarding the publication of this paper.

\section{References}

[1] A. Alani, M. Kelleher, and K. Bishop, "Peri-implantitis. Part 1: scope of the problem," British Dental Journal, vol. 217, no. 6, pp. 281-287, 2014.

[2] N. U. Zitzmann and T. Berglundh, "Definition and prevalence of peri-implant diseases," Journal of Clinical Periodontology, vol. 35, no. 8, pp. 286-291, 2008.

[3] M. A. Atieh, N. H. M. Alsabeeha, C. M. Faggion Jr., and W. J. Duncan, "The frequency of peri-implant diseases: a systematic review and meta-Analysis," Journal of Periodontology, vol. 84, no. 11, pp. 1586-1598, 2013.

[4] L. Canullo, D. Peñarrocha-Oltra, U. Covani, D. Botticelli, G. Serino, and M. Penarrocha, "Clinical and microbiological findings in patients with peri-implantitis: a cross-sectional study," Clinical Oral Implants Research, 2015.

[5] H. J. Meijer, G. M. Raghoebar, Y. C. M. de Waal, and A. Vissink, "Incidence of peri-implant mucositis and peri-implantitis in edentulous patients with an implant-retained mandibular overdenture during a 10-year follow-up period," Journal of Clinical Periodontology, vol. 41, no. 12, pp. 1178-1183, 2014.

[6] A. Mombelli, D. Buser, and N. P. Lang, "Colonization of osseointegrated titanium implants in edentulous patients. Early results," Oral Microbiology and Immunology, vol. 3, no. 3, pp. 113-120, 1988.

[7] W. Becker, B. E. Becker, M. G. Newman, and S. Nyman, "Clinical and microbiologic findings that may contribute to dental implant failure," The International Journal of Oral \& Maxillofacial Implants, vol. 5, no. 1, pp. 31-38, 1990.

[8] G. A. Alcoforado, T. E. Rams, D. Feik, and J. Slots, "Microbial aspects of failing osseointegrated dental implants in humans," Journal de Parodontologie, vol. 10, no. 1, pp. 11-18, 1991.

[9] H. F. Jenkinson and R. J. Lamont, "Oral microbial communities in sickness and in health," Trends in Microbiology, vol. 13, no. 12, pp. 589-595, 2005.

[10] F. E. Dewhirst, T. Chen, J. Izard et al., "The human oral microbiome," Journal of Bacteriology, vol. 192, no. 19, pp. 50025017, 2010.

[11] M. Muthukuru, A. Zainvi, E. O. Esplugues, and T. F. Flemmig, "Non-surgical therapy for the management of peri-implantitis: a systematic review," Clinical Oral Implants Research, vol. 23, supplement 6, pp. 77-83, 2012.

[12] S. Renvert, I. Polyzois, and N. Claffey, "Surgical therapy for the control of peri-implantitis," Clinical Oral Implants Research, vol. 23, no. 6, pp. 84-94, 2012.

[13] M. Esposito, M. G. Grusovin, and H. V. Worthington, "Treatment of peri-implantitis: what interventions are effective? A Cochrane systematic review," European journal of oral implantology, vol. 5, supplement, pp. S21-S41, 2012.

[14] A. Mombelli, R. Moëne, and F. Décaillet, "Surgical treatments of peri-implantitis," European Journal of Oral Implantology, vol. 5, pp. S61-70, 2012.

[15] K. Subramani and D. Wismeijer, "Decontamination of titanium implant surface and re-osseointegration to treat periimplantitis: a literature review," The International Journal of Oral \& Maxillofacial Implants, vol. 27, no. 5, pp. 1043-1054, 2012.

[16] J.-J. Suh, Z. Simon, Y.-S. Jeon, B.-G. Choi, and C.-K. Kim, "The use of implantoplasty and guided bone regeneration in the treatment of peri-implantitis: two case reports," Implant Dentistry, vol. 12, no. 4, pp. 277-282, 2003.

[17] N. P. Lang, T. G. Wilson, and E. F. Corbet, "Biological complications with dental implants: their prevention, diagnosis and 
treatment," Clinical Oral Implants Research, vol. 11, supplement 1, pp. 146-155, 2000.

[18] R. A. Urdaneta, S. Rodriguez, D. C. McNeil, M. Weed, and S.K. Chuang, "The effect of increased crown-to-implant ratio on single-tooth locking-taper implants," The International Journal of Oral \& Maxillofacial Implants, vol. 25, no. 4, pp. 729-743, 2010.

[19] L. J. Heitz-Mayfield and A. Mombelli, "The therapy of periimplantitis: a systematic review," The International Journal of Oral \& Maxillofacial Implants, vol. 29, supplement, pp. 325-345, 2014.

[20] N. P. Lang, T. Berglundh, L. J. Heitz-Mayfield, B. E. Pjetursson, G. E. Salvi, and M. Sanz, "Consensus statements and recommended clinical procedures regarding implant survival and complications," International Journal of Oral and Maxillofacial Implants, vol. 19, pp. 150-154, 2004.

[21] S. Parma-Benfenati, M. Roncati, and C. Tinti, "Treatment of peri-implantitis: surgical therapeutic approaches based on periimplantitis defects," International Journal of Periodontics and Restorative Dentistry, vol. 33, no. 5, pp. 627-633, 2013.

[22] M. H. Zablotsky, D. L. Diedrich, and R. M. Meffert, "Detoxification of endotoxin-contaminated titanium and hydroxyapatite-coated surfaces utilizing various chemotherapeutic and mechanical modalities," Implant Dentistry, vol. 1, no. 2, pp. 154158, 1992.

[23] P. L. Parham Jr., C. M. Cobb, A. A. French, J. W. Love, C. L. Drisko, and W. J. Killoy, "Effects of an air-powder abrasive system on plasma-sprayed titanium implant surfaces: an in vitro evaluation," The Journal of Oral Implantology, vol. 15, no. 2, pp. 78-86, 1989.

[24] D. K. Dennison, M. B. Huerzeler, C. Quinones, and R. G. Caffese, "Contaminated implant surfaces: an in vitro comparison of implant surface coating and treatment modalities for decontamination," Journal of Periodontology, vol. 65, no. 10, pp. 942-948, 1994.

[25] P. Sahrmann, V. Ronay, D. Hofer, T. Attin, R. E. Jung, and P. R. Schmidlin, "In vitro cleaning potential of three different implant debridement methods," Clinical Oral Implants Research, vol. 26, no. 3, pp. 314-319, 2015.

[26] A. C. de Mendonça, V. R. Santos, J. B. César-Neto, and P. M. Duarte, "Tumor necrosis factor-alpha levels after surgical antiinfective mechanical therapy for peri-implantitis: a 12-month follow-up," Journal of Periodontology, vol. 80, no. 4, pp. 693-699, 2009.

[27] M. B. Máximo, A. C. De Mendonça, V. Renata Santos, L. C. Figueiredo, M. Feres, and P. M. Duarte, "Short-term clinical and microbiological evaluations of peri-implant diseases before and after mechanical anti-infective therapies," Clinical Oral Implants Research, vol. 20, no. 1, pp. 99-108, 2009.

[28] P. M. Duarte, A. C. de Mendonça, M. B. B. Máximo, V. R. Santos, M. F. Bastos, and F. H. Nociti Jr., "Effect of anti-infective mechanical therapy on clinical parameters and cytokine levels in human peri-implant diseases," Journal of Periodontology, vol. 80, no. 2, pp. 234-243, 2009.

[29] M. Kreisler, W. Kohnen, A.-B. Christoffers et al., "In vitro evaluation of the biocompatibility of contaminated implant surfaces treated with an Er:YAG laser and an air powder system," Clinical Oral Implants Research, vol. 16, no. 1, pp. 3643, 2005.

[30] F. Schwarz, D. Ferrari, K. Popovski, B. Hartig, and J. Becker, "Influence of different air-abrasive powders on cell viability at biologically contaminated titanium dental implants surfaces,"
Journal of Biomedical Materials Research Part B: Applied Biomaterials, vol. 88, no. 1, pp. 83-91, 2009.

[31] P. Sahrmann, V. Ronay, B. Sener, R. E. Jung, T. Attin, and P. R. Schmidlin, "Cleaning potential of glycine air-flow application in an in vitro peri-implantitis model," Clinical Oral Implants Research, vol. 24, no. 6, pp. 666-670, 2013.

[32] S. J. Froum, S. H. Froum, and P. S. Rosen, "Successful management of peri-implantitis with a regenerative approach: a consecutive series of 51 treated implants with 3- to 7.5-year follow-up," The International Journal of Periodontics \& Restorative Dentistry, vol. 32, no. 1, pp. 11-20, 2012.

[33] S. Porter, K. Al-Johani, S. Fedele, and D. Moles, "Randomised controlled trial of the efficacy of HybenX in the symptomatic treatment of recurrent aphthous stomatitis," Oral Diseases, vol. 15, no. 2, pp. 155-161, 2009.

[34] R. Dimitriou, G. I. Mataliotakis, G. M. Calori, and P. V. Giannoudis, "The role of barrier membranes for guided bone regeneration and restoration of large bone defects: current experimental and clinical evidence," BMC Medicine, vol. 10, article 81, 2012.

[35] R. P. Meinig, "Clinical use of resorbable polymeric membranes in the treatment of bone defects," Orthopedic Clinics of North America, vol. 41, no. 1, pp. 39-47, 2010.

[36] A.-M. Roos-Jansåker, C. Lindahl, G. R. Persson, and S. Renvert, "Long-term stability of surgical bone regenerative procedures of peri-implantitis lesions in a prospective case-control study over 3 years," Journal of Clinical Periodontology, vol. 38, no. 6, pp. 590-597, 2011. 


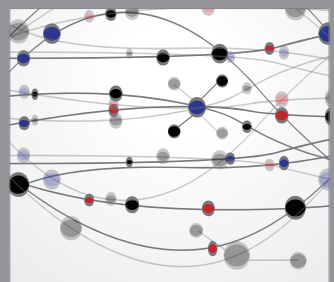

The Scientific World Journal
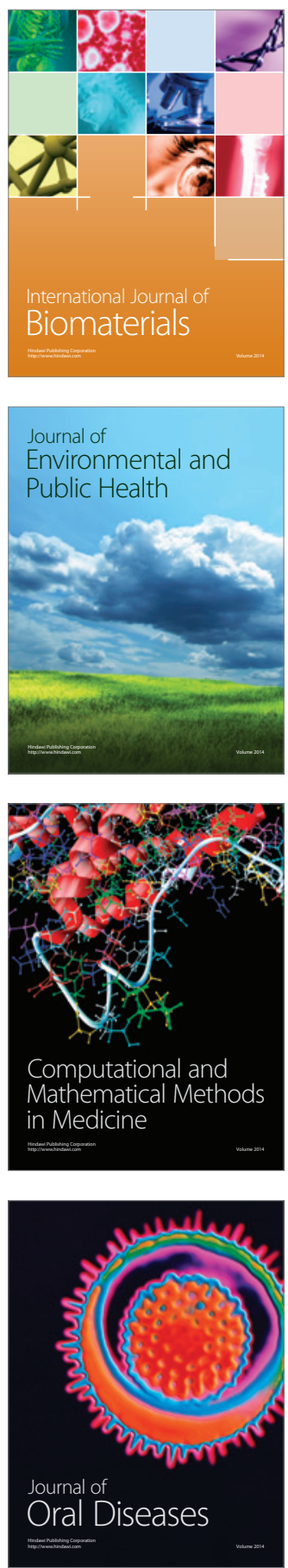
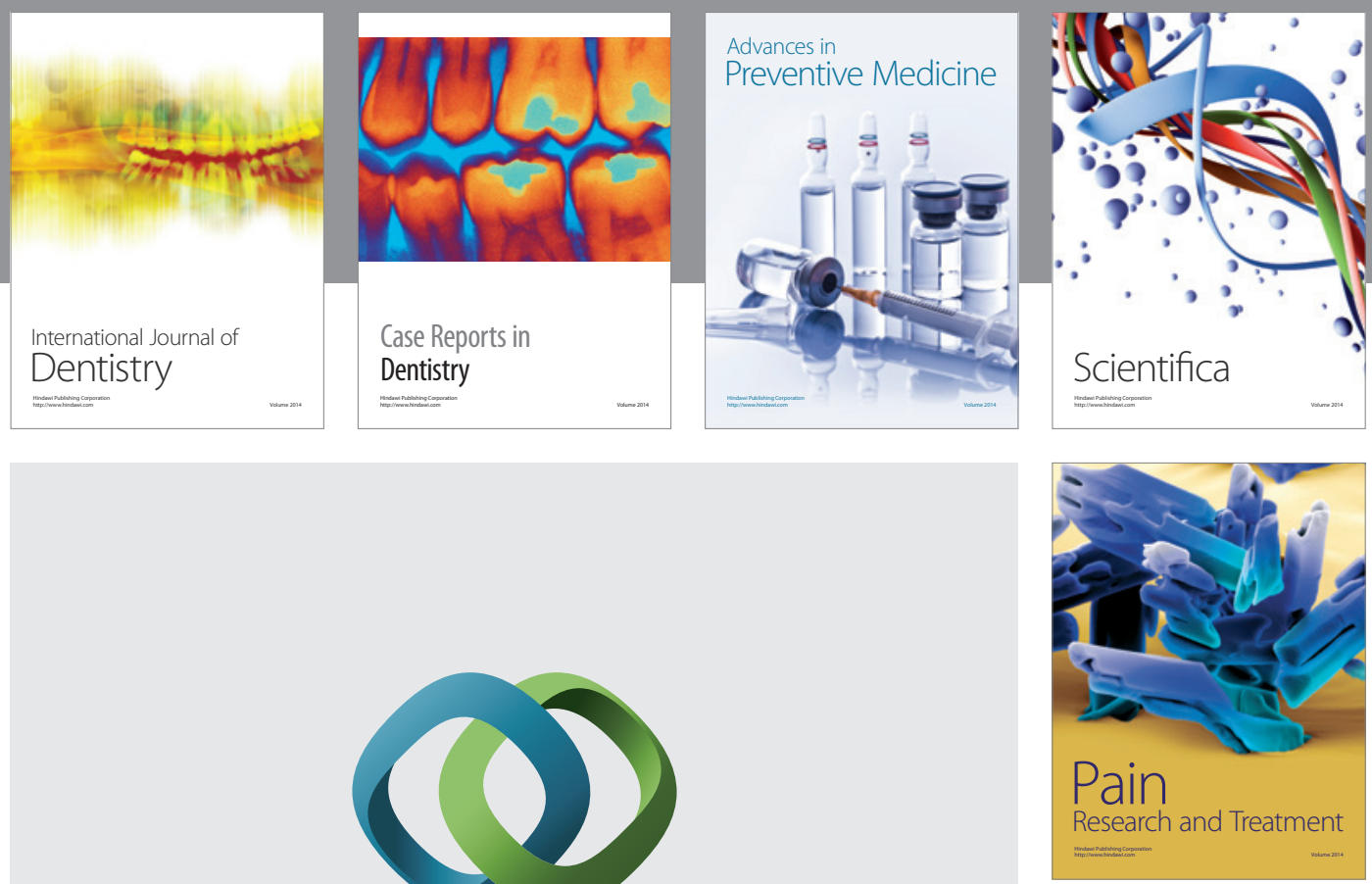

\section{Hindawi}

Submit your manuscripts at

http://www.hindawi.com
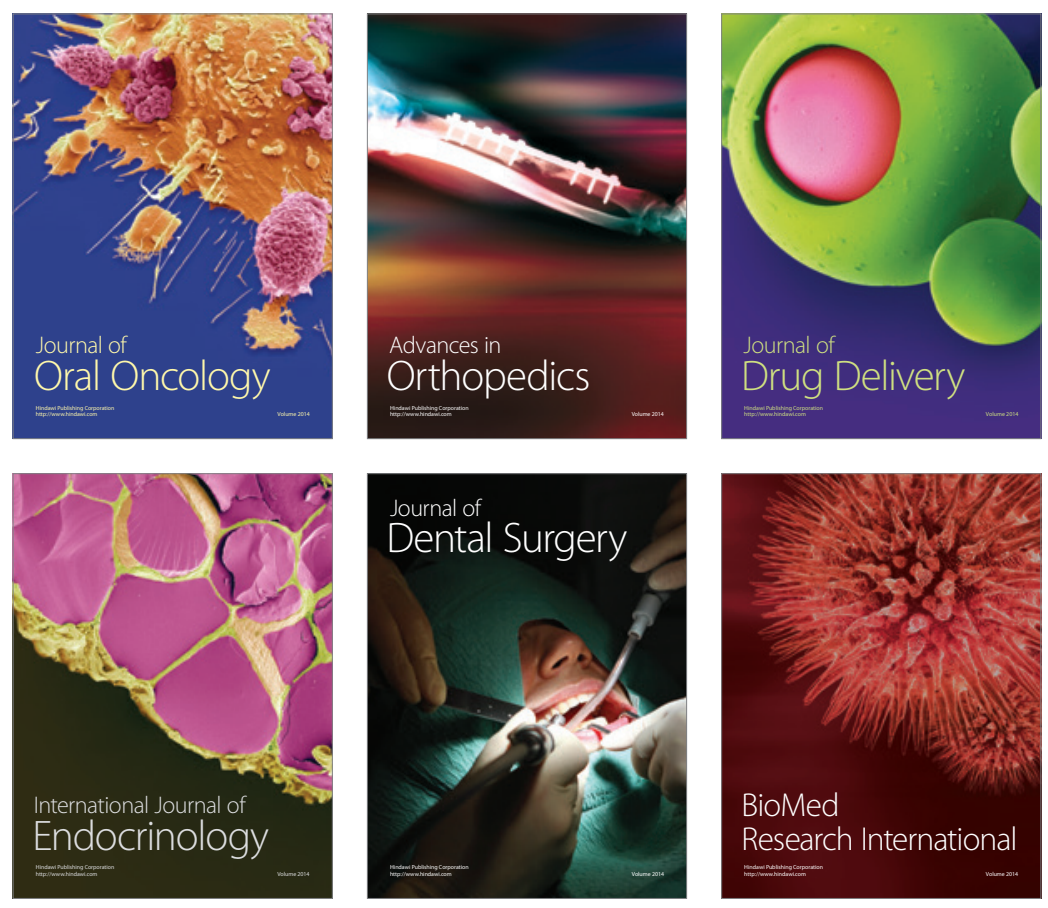

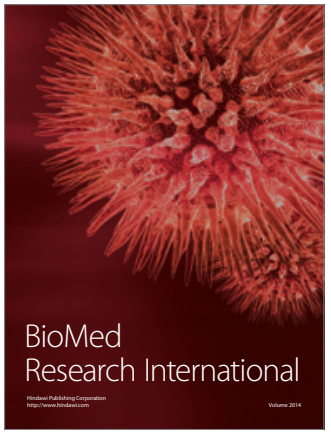

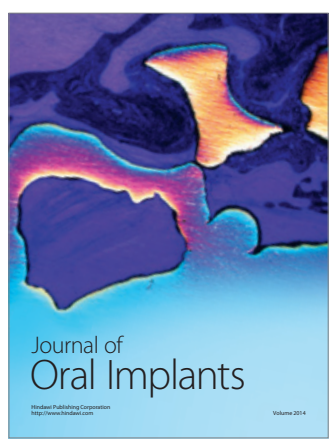
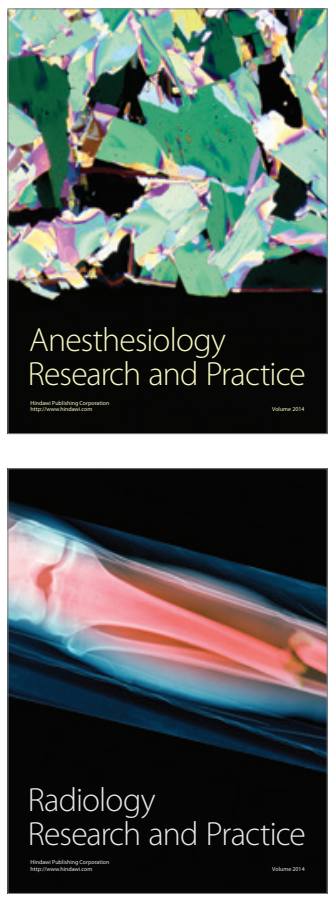